\title{
Causalidade entre Renda e Saúde: Uma Análise Através da Abordagem de Dados em Painel com os Estados do Brasil ${ }^{\star}$
}

\author{
Anderson Moreira Aristides dos Santos \\ Professor - Universidade Federal de Alagoas (Campus Sertão) \\ Unidade Santana do Ipanema - AL \\ Endereço para contato: Rua Prefeito Adeildo Nepomuceno Marques, 472 - Bairro Monumento \\ Santana do Ipanema - Alagoas - CEP: 57500-000 \\ E-mail: anderson_moreira_aristides@hotmail.com
}

\section{Paulo de Andrade Jacinto}

Professor - Programa de Pós-Graduação em Economia (PPGE/PUCRS)

Faculdade de Administração, Contabilidade e Economia (FACE)

Av. Ipiranga, 6681 - Caixa Postal 1429 - Porto Alegre / RS - CEP 90619-900

E-mail: paulo.jacinto@pucrs.br

\section{César Augusto Oviedo Tejada}

Professor - Programa de Pós-Graduação em Organizações e Mercados (PPGOM/UFPel)

Rua Gomes Carneiro, $014^{\circ}$ andar - Centro - Pelotas/RS - CEP: 96010-610

E-mail: cesartejada9@hotmail.com

Recebido em 09 de abril de 2011. Aceito em 28 de fevereiro de 2012.

\section{Resumo}

Este trabalho tem o objetivo de analisar a relação de causalidade entre renda e saúde, buscando controlar as potenciais diferenças dessa relação ao longo do território brasileiro. Para tanto, três testes de causalidade de Granger para dados em painel, propostos respectivamente por Holtz-Eakin et al. (1988), Granger e Huang (1997) e Hurlin $(2005,2007)$, são aplicados para uma base de dados com os estados brasileiros, no período compreendido entre 1981-2007. Os principais resultados mostram que as conclusões podem ser enganosas quando são baseadas em testes com uma estrutura homogênea nos parâmetros. E assim, o teste proposto por Hurlin $(2005,2007)$, que controla os diferentes tipos de heterogeneidade, aponta que, no Brasil, as evidências são mais claras para causalidade no sentido da saúde para a renda.

\section{Palavras-Chave}

renda, saúde, causalidade de Granger, dados em painel

- Este trabalho é baseado na dissertação do primeiro autor no CMEA/UFAL no qual foi bolsista Capes, fica o agradecimento a este fomento. Agradecemos aos comentários de Tatiane Menezes na fase de dissertação e de todas as sugestões dos participantes do XXXVIII Encontro Nacional da ANPEC, e ainda, aos comentários e sugestões dos pareceristas anônimos. Fica registrada também a gratidão ao apoio da bolsista PIBIC/CNPQ Fernanda Ewerling. Todos os erros e omissões são totalmente responsabilidade dos autores. 


\begin{abstract}
This paper aims to analyze causality relationship between income and health, seeking to control the potential differences of this relation over the Brazilian territory. Three tests for Granger causality in panel data, proposed respectively by Holtz-Eakin et al. (1988), Granger and Huang (1997) and Hurlin (2005, 2007), are applied to a database of Brazilian states over the period 1981-2007. The main results show that conclusions can be misleading when they are based on the causality tests with homogeneous structure parameters. And so, the test proposed by Hurlin $(2005,2007)$, which controls the different types of heterogeneity, indicates that in Brazil the evidence is clearer for causality in direction from health to income.
\end{abstract}

\title{
Keywords
}

income, health, Granger causality, panel data

\section{JEL Classification}

$110,118,132$

\section{Introdução}

Como as melhorias na renda e na saúde estão ligadas ao aumento do bem-estar social, entender a relação de causalidade entre essas duas dimensões é de fundamental importância. Por isso, o objetivo deste estudo é analisar a relação de causalidade entre renda e saúde, buscando controlar as possíveis diferenças dessa relação com o uso de dados dos estados brasileiros. Estudos como de Posnett e Hitiris (1992), Knowles e Owen (1995), Sala-i-Martin et al. (2004), Bloom et al. (2004), Soares (2006), entre outros, demonstraram que não há um consenso e as evidências encontradas na literatura sugerem que há duas hipóteses de identificação ou, ainda, uma terceira, em que contempla a aceitação de ambas.

A primeira, parte do argumento de que a renda afeta a saúde, já que um maior nível de renda permite gozar de melhor status de saúde. As formas pelas quais a renda afeta a saúde podem ser entendidas pelo uso da renda na aquisição de bens e serviços de saúde, acesso aos serviços de saúde, condições de moradia e da educação.

A causalidade também poderia ser na direção oposta. Assim, a segunda hipótese de identificação parte do argumento de que a saúde afeta a renda. Como o capital humano é um insumo associado com a capacidade da força de trabalho, a saúde impacta diretamente sobre a produtividade e oferta de trabalho afetando o crescimento econô- 
mico. Os impactos indiretos sobre a renda e sua taxa de crescimento se dão por meio da acumulação de capital físico e capital humano na forma de educação.

Estudos como Sala-i-Martin (2005) e Chen (2008) defendem que essa relação é bi-causal, uma vez que um baixo nível de renda causa saúde precária e essa, por sua vez, tende a causar um baixo nível de renda, gerando um círculo vicioso chamado de armadilha saúde-pobreza. Porém, há controvérsias a respeito de lugares com baixo nível de renda (e alto nível de pobreza) possuírem população com saúde precária. Poderia ser argumentado que nesses lugares seria necessário aumentar o nível de renda para melhorar a saúde da população, ao passo que para combater o baixo nível de renda (e alto nível de pobreza) seria necessário melhorar o nível de saúde da população.

Nos últimos anos no Brasil, a literatura econômica sobre o tema saúde vem crescendo, e muito. Estudos como o de Kassouf (1994), Alves e Andrade (2003), Alves e Beluzzo (2004), Soares (2007), Reis e Crespo (2009) e Noronha et al. (2010), entre outros, partiram da hipótese de identificação de que renda causa saúde ou a saúde causa renda. Nesse sentido, o presente estudo procura contribuir com essa literatura ao analisar a relação de causalidade entre renda e saúde. Para tanto, serão aplicados três testes de causalidade no sentido de Granger, propostos por Holtz-Eakin et al. (1988), Granger e Huang (1997) e Hurlin $(2005,2007)$ em um painel de dados com estados do Brasil no período de 1981 a 2007.

Além desta breve introdução, o trabalho está dividido em quatro seções. A segunda seção apresenta a relação teórica de causalidade entre renda e saúde, além de algumas evidências empíricas. A terceira seção apresenta a metodologia utilizada neste trabalho. A quarta seção analisa brevemente correlações entre renda e saúde, e faz uma análise dos resultados dos testes de causalidade. Por fim, a quinta seção faz as considerações finais.

\section{Causalidade entre Renda e Saúde: Uma Breve Revisão ${ }^{1}$}

Os estudos sobre causalidade entre renda e saúde têm sido desenvolvidos em duas direções distintas, porém complementares. Uma delas

\footnotetext{
Baseado em parte em Sala-i-Martin (2005).
} 
está direcionada ao desenvolvimento de aspectos teóricos, ${ }^{2}$ ao passo que a outra visa acrescentar a base empírica a essas formulações.

A seguir apresenta-se uma breve revisão da literatura em termos teóricos e empíricos.

\subsection{Teoria}

$\mathrm{Na}$ literatura econômica as teorias que procuram entender a relação entre renda e saúde podem ser reunidas em dois grupos. O primeiro apresenta uma série de estudos em que a renda causa a saúde. $\mathrm{Na}$ direção oposta a esse grupo, o segundo busca entender como a saúde causa a renda. Por isso, vamos apresentar os principais argumentos que são empregados para justificar essa relação de causalidade entre renda e saúde.

O primeiro argumento empregado para justificar a causalidade na direção de renda para saúde mostra que as pessoas com maior renda têm maior possibilidade de adquirir bens e serviços de saúde, tais como: consultas médicas, medicamentos e planos de saúde. Dessa forma, as pessoas mais ricas podem dispor de exames preventivos, e/ou, quando diagnosticada uma doença, podem ter acesso ao tratamento necessário. No Brasil, alguns trabalhos que mostram os indivíduos de baixa renda demandam menos os serviços de saúde, principalmente a parte que se refere à saúde preventiva (IBGE, 2005, Almeida et al., 2000; Noronha; Andrade, 2002; Neri, Soares, 2002).

Por esse ponto de vista, o sistema público de saúde no Brasil tem fundamental importância na tentativa de redução das desigualdades do acesso à saúde. Espera-se que o SUS ao melhorar sua qualidade e eficácia seja benéfico a toda a população, principalmente aos mais pobres que são aparentemente os que mais necessitam do serviço público de saúde. Porém, mesmo supondo eficácia e qualidade do SUS, a renda ainda pode continuar tendo influência sobre a saúde pelo simples fato de que os pobres têm maior probabilidade de sofrer choques negativos na saúde (Crespo; Reis, 2008). Por exemplo, com um maior nível de renda, as pessoas podem adquirir bens básicos como os alimentos e, dessa forma, reduzir ou erradicar a desnutrição

2 Os trabalhos de Kalemli-Ozcan (2002), Chakraborty (2004), Soares (2005) e Chen (2008) são alguns dos estudos que desenvolvem modelos teóricos que analisam a relação entre saúde e renda por diversos caminhos, explorando alguns resultados em comum. 
e/ou a insegurança alimentar. (Alvez; Belluzzo, 2004, Monteiro et al., 2009, Crespo; Reis, 2008). Assim, as políticas públicas de transferência de renda melhorariam o estado de saúde dos indivíduos mais pobres (Camelo et al., 2009).

Outro argumento que mostra como renda afeta saúde emprega a sua relação com boas condições de moradia, como acesso à água potável e esgotamento sanitário. É provável que as pessoas mais pobres morem em lugares com condições precárias de saneamento básico e que sejam mais vulneráveis a doenças, principalmente as crianças. As principais doenças ligadas à falta de saneamento são cólera, infecções gastrintestinais, febre tifoide, poliomielite, amebíase, esquistossomose e shiguelose (Mendonça; Seroa Da Motta, 2005).

É comum também utilizar o argumento da falta de renda parar explicar essa relação de que a renda causa saúde. Essa influência ocorre da seguinte forma: mesmo havendo bens e serviços públicos de saúde, os pobres algumas vezes não têm acesso a estes, já que moram distantes de hospitais, sendo muito caro buscar ajuda quando aparecem as enfermidades ou, até mesmo, para questões como um parto. Logo, os pobres têm maior possibilidade de não ter acesso a serviços preventivos de saúde e a tratamentos e, portanto, terem saúde precária. Neste caso, destaca-se o importante papel do Programa Saúde da Família no que se refere às questões mais básicas de saúde. ${ }^{3,4}$

Por fim, as pessoas com maior renda têm maior nível de educação e informação, com isso entendem a necessidade de hábitos saudáveis e questões de higiene. A favor desse argumento há inúmeras evidências mostrando que um dos principais determinantes da saúde infantil é a escolaridade das mães. (Kassouf, 1994, Alves; Belluzzo, 2004; Mendonça; Seroa Da Motta, 2005, Monteiro et al., 2009).

Em suma, há diversos argumentos mostrando como a renda causa saúde. Mas a causalidade também vai à outra direção, isto é, a saúde causa renda. A teoria econômica mostra que a saúde tem efeitos diretos e efeitos indiretos sobre a renda e seu crescimento. O efeito di-

3 O PSF foi implantado pelo Ministério da Saúde em 1994 com objetivo de garantir o acesso aos cuidados primários de saúde, assegurando os princípios do SUS de universalidade, integralidade, equidade e participação social.

Para mais detalhes ver: http://dtr2004.saude.gov.br/dab/atencaobasica.php.

4 Macinko e Guanais (2005) mostram que o PSF teve grande importância na redução da mortalidade infantil no Brasil entre 1981-2002. 
reto se dá na saúde como uma forma de capital humano. Os efeitos indiretos ocorrem através da educação (outro componente do capital humano) e do capital físico. A seguir são descritos esses efeitos.

Primeiramente, o efeito direto ocorre através do impacto da saúde sobre a produtividade e a oferta de trabalho. Observa-se que pessoas com saúde precária diminuem a oferta de trabalho. Além de possuírem baixa produtividade, esse mecanismo tende a reduzir os salários dessas pessoas (Alves; Andrade, 2003, Schultz, 2002). Macroeconomicamente, esses efeitos também são evidenciados em termos de renda agregada (Bloom et al., 2004, Bloom et al., 2005; Weil, 2007).

Segundo, a saúde tem efeitos sobre a educação como um componente do capital humano. Neste caso têm-se os seguintes mecanismos:

i) as crianças doentes têm um menor nível de aprendizagem, além de perderem aula frequentemente (Machado, 2008; Alderman et al.,1997). Essas crianças obtêm menor nível de educação, aumentando a probabilidade de serem ou continuarem pobres no futuro;

ii) a saúde afeta a educação através do tradeoff beckeriano quantidade-qualidade das crianças. Pais que sabem que existe uma grande probabilidade de seus filhos morrerem precocemente tendem a ter muitas crianças. Contudo, uma maior quantidade leva a uma menor qualidade, já que a família terá menos recursos dedicados por filho, com isso as crianças terão menor investimento em educação e uma baixa acumulação de capital humano (Kalemli-Ozcan, 2003 e Soares, 2005);

iii) a saúde também afeta a educação através da maior expectativa de vida ao estimular investimento em educação. Isso é explicado devido ao retorno do capital humano na forma de educação como custo de investimento descontado dos salários futuros. Portanto, se as pessoas esperam viver mais, terão expectativas de maiores retornos em termos de salários (Kalemli-Ozcan et al., 2000; Chakraborty, 2004; Jayachandran; Lleras-Muney, 2009); ${ }^{5}$ e

iv) a saúde tem influência sobre educação através da morte precoce dos pais. O processo de educação tem custos, requerendo materiais escolares, tempo do estudante, mensalidades no caso de

5 Empiricamente Soares (2006), com dados em nível individual, do Brasil, do ano de 1996, mostra evidências de uma maior longevidade estar associada a um maior nível de escolaridade e menor fertilidade. 
escolas particulares, entre outros elementos. O grupo familiar é de extrema importância para o estudante adquirir esses elementos. Portanto, se os pais morrem precocemente, aumenta a possibilidade de o jovem ter que ingressar no mercado de trabalho, reduzindo o tempo investido em educação através do abandono ou redução do estudo.

A saúde também afeta a acumulação de capital físico. Neste caso, têm-se basicamente os seguintes mecanismos:

i) os cidadãos que esperam viver muito depois da aposentadoria tendem a ter fortes incentivos para poupar e investir. Portanto, quanto melhor a saúde da população e maior a expectativa de vida, maior tende a ser a acumulação de capital físico da economia. (Chakraborty, 2004; Chen, 2008); ${ }^{6}$

ii) a saúde também afeta acumulação de capital físico através da complementaridade entre os insumos. Quando há tal complementaridade, quanto melhor a saúde, maior a acumulação de capital humano - seja diretamente através do capital humano na forma de saúde ou indiretamente através da relação entre saúde e educação - existe um maior incentivo para as firmas investirem em capital físico;

iii) O efeito da saúde sobre o capital físico se dá também através do investimento público. Se uma grande parte da população tem saúde precária e não tem recursos monetários necessários para tratamentos, resta ao governo aumentar os gastos para suprir a maior demanda por bens e serviços de saúde, levando a uma redução da poupança do governo e de investimento em infraestrutura, que afeta os incentivos do setor privado de investir em capital físico. ${ }^{7}$

Diante da implicação da causalidade da saúde sobre a renda, políticas públicas com o objetivo de aumentar a renda e reduzir a pobreza através de melhorias na educação, acumulação de capital físico entre outras, podem não ter o efeito desejado se a saúde da população não for levada em consideração.

6 Empiricamente Lorentzen et al. (2008) através de dados cross-country acham que a mortalidade afeta o crescimento econômico em grande magnitude e um dos principais canais para esse efeito é o capital físico.

7 Além disso, o fato de uma grande parte da população possuir saúde precária, e, consequentemente, baixa renda, afeta a arrecadação do governo, diminuindo sua disponibilidade de recursos no sistema público de saúde, o que volta a afetar a saúde da população. O modelo de Chakraborty (2004) mostra esse mecanismo. 
Em resumo, os argumentos acima descritos sugerem uma relação bidirecional entre a saúde e a renda. Com isso, uma baixa renda reflete em saúde precária e vice-versa, podendo criar um círculo vicioso, em que a sociedade ou um indivíduo é pobre, porque tem saúde precária, e tem saúde precária, porque é pobre. ${ }^{8}$

\subsection{Evidências Empíricas}

Os estudos empíricos que analisam o impacto da renda sobre a saúde em um nível macro com amostras entre países, Posnett e Hitiris (1992) e Pritchett e Summers (1996), mostram que a renda é importante na explicação das diferenças na saúde. Para o Brasil, Soares (2007) analisa os determinantes da expectativa de vida em um painel de dados com municípios, entre 1970-2000, e mostra que dos $71 \%$ na variação na esperança de vida presenciadas no período, 33\% são explicadas por mudanças na renda per capita. Alves e Belluzzo (2004), também analisando os municípios nesse mesmo período, encontram que a renda é um dos importantes determinantes da mortalidade infantil. Com o uso de microdados, Reis e Crespo (2009) mostram que, no Brasil, crianças que vivem em domicílios pobres apresentam piores condições de saúde e concluem que essa relação pode ser um importante transmissor intergeracional de desigualdade de renda e contribuir para persistência da pobreza. ${ }^{9}$

Contudo, a partir do início da década de 90, alguns trabalhos passam a analisar o efeito contrário, ou seja, o impacto da saúde sobre a renda. Os estudos de Knowles e Owen (1995), Bloom et al. (2004), ${ }^{10}$ Sala-i-Martin et al. (2004), Lorentzen et al. (2008), entre outros, mostram um efeito positivo, forte e robusto da saúde sobre o crescimento da renda per capita. Em relação à literatura nacional, Noronha et al. (2010) através de um painel com os estados brasileiros, entre 1991-2000, mostram que a saúde tem um impacto positivo sobre o crescimento econômico e que reduções da taxa de mortalidade infantil estão intimamente relacionadas a maiores taxas de crescimento da renda. ${ }^{11}$

8 Para uma análise de modelos teóricos que mostram como a relação bi-causal entre renda e saúde pode se refletir em armadilha da pobreza, ver Chakraborty (2004) e Chen (2008).

9 Para um trabalho que explica bem essa transmissão intergeracional que pode ocorrer da relação causal entre renda domiciliar e saúde na infância, ver Case et al. (2002).

${ }^{10} \mathrm{O}$ estudo de Bloom et al. (2004) traz uma tabela resumo de vários estudos que analisam o impacto da saúde sobre o crescimento da renda.

${ }^{11}$ Para um trabalho que mostra a importância da saúde sobre os rendimentos individuais para 
É comum nesses estudos olhar as correlações, porém as altas correlações entre renda e saúde nada dizem sobre a causalidade, sendo necessária uma análise da precedência ou causalidade de Granger. Brinkley (2003) analisa causalidade entre renda e saúde, utilizando produto nacional bruto a preços constantes, índices de mortalidade e expectativa de vida para os Estados Unidos para uma série de tempo, a partir da metade do século XIX. Os resultados encontrados indicam que a causalidade no sentido de Granger é mais bem explicada na direção de saúde sobre a renda. Resultado semelhante é obtido em Michaud e Van Soest (2004) em uma análise com microdados de uma coorte de idosos dos EUA. Anterior a esse estudo, mas com uma estrutura de dados similar, Adams et al. (2003) encontram resultados favoráveis a uma relação bidirecional entre renda e saúde. ${ }^{12}$

Há estudos com o objetivo de verificar essa relação de causalidade entre países. Devlin e Hansen (2001) testam causalidade de Granger para 20 países da OCDE para examinar a exogeneidade do PIB que é assumido em pesquisa dos determinantes de gastos em cuidados médicos. Os autores concluem que as despesas com cuidados médicos causam PIB no sentido de Granger e vice-versa. Também analisando dados em painel com países da OCDE, Hartwig (2009) testa causalidade entre formação de capital saúde e crescimento econômico de longo prazo para o período de 1970-2005. Os principais resultados mostram que há evidências de que a formação de capital saúde - seja através dos gastos com cuidados em saúde ou através de aumentos na expectativa de vida - Granger causa crescimento do PIB per capita com sinal contrário do esperado, ou seja, negativo. Já a causalidade no sentido contrário se encontra significativa e com sinal positivo.

Erdil e Yetkiner (2009), com o uso de um painel de dados com 75 países e para o período de 1990 a 2000, testam a causalidade de Granger entre PIB e despesas per capita com saúde. Para tanto, utilizam o teste proposto por Hurlin e Venet (2001) que controla a heterogeneidade na relação de causalidade. Os resultados indicam que o tipo dominante de causalidade é bidirecional. Contudo, os autores também encontram evidências de causalidade do PIB para gastos per capita com saúde para alguns países dos grupos de renda baixa e de

o Brasil, ver Alves e Andrade (2003).

${ }^{12}$ Michaud e Van Soest (2004) utilizaram uma extensão do teste de causalidade de Granger de Adams et al. (2003), através da incorporação de uma estrutura de painel dinâmico e do controle das heterogeneidades não observadas. Essa diferença de metodologia determinou as diferenças nos resultados desses dois trabalhos. 
renda média e causalidade inversa dos gastos per capita com saúde para o PIB em alguns países do grupo de renda alta.

Por fim, Chen (2008), utilizando informações quinquenais de 105 países em desenvolvimento para o período de 1960 e 2000, testa a relação entre renda e saúde empregando três testes: Holtz Eakin et al. (1988); Hurlin $(2005,2007)$ e; Weinhold (1999) e Nair Reichert e Weinhold (2001). Os resultados, em geral, também mostram que a causalidade entre renda e saúde é bidirecional. Contudo, esses resultados parecem estar mais relacionados a países de renda média do que países de renda baixa. Nos testes que consideram heterogeneidade de causalidade, os países de renda baixa apresentaram uma relação de não causalidade entre renda e saúde.

\section{Metodologia}

Esta seção está dividida em quatro subseções. A primeira subseção apresenta os testes para raiz unitária e as três subseções seguintes apresentam os três diferentes testes de causalidade que serão utilizados neste trabalho. Todos os testes que serão aplicados se referem à causalidade no sentido de Granger. O conceito desta está relacionado com a capacidade de uma variável ajudar na previsão do comportamento de outra variável de interesse. Não se trata de uma causalidade no sentido estrito, em que uma variável determina o comportamento da outra ou na noção de uma variação controlada, ${ }^{13}$ mas sim da existência de uma precedência temporal, tendo como pré-requisito que essa precedência venha ser estatisticamente significativa.

A sua aplicação aos modelos de séries de tempo é extensa, aos modelos que utilizam dados em painel ainda é relativamente recente. Entre as vantagens da utilização de dados em painel pode ser destacado o maior número de observações, que aumenta os graus de liberdade e reduz o grau de colinearidade entre variáveis explicativas e, consequentemente, melhora a eficiência do parâmetro estimado. Este tipo de técnica auxilia na análise de várias perguntas econômicas que não podem ser respondidas, utilizando somente dados de corte

\footnotetext{
${ }^{13}$ Nesse caso, o objetivo da inferência causal reside em avaliar se a manipulação de um tratamento, mantendo todos os outros fatores constantes, afeta o resultado. Ver Rubin (1976, 1986), Heckman $(2000,2008)$ e Holland (1986). Trata-se de um conceito distinto de outras noções de causalidade que se baseiam na previsão como a de Granger (1969) e Sims (1972).
} 
transversal ou em séries de tempo. Além disso, a análise com dados em painel gera predições mais precisas de resultados individuais em relação a séries de tempo, porque em um painel o comportamento de um indivíduo pode ser aprendido tanto pelo comportamento próprio como observando o comportamento dos demais (Hsiao, 2003).

Para Chen (2008), o maior desafio no uso do teste de causalidade de Granger com painel de dados se deve à relação causal entre $\mathrm{X}$ e $Y$, que pode ser diferente entre os estados. Além do teste proposto por Holtz-Eakin et al. (1988) e de Granger e Huang (2003), que permite controlar heterogeneidade entre estados, nestes casos por efeitos fixos, é utilizado o teste de Hurlin $(2005,2007)$, que além de controlar estimações através de efeitos fixos, permite controlar heterogeneidade dos parâmetros de estimação.

Os testes de raiz unitária e os de causalidade serão aplicados para a variável renda domiciliar per capita, representante da renda, retirada do Ipeadata ${ }^{14,15}$ e para taxa de mortalidade na infância (menores de 5 anos), variável representante da saúde, retirada do Datasus. ${ }^{16,17}$ Ambas as variáveis foram obtidas para os 25 estados do Brasil mais o Distrito Federal ${ }^{18}$ e devido à disponibilidade de dados, para o período de 1981 a 2007.

Cabe destacar que, apesar de a taxa de mortalidade na infância estar restrita a uma determinada faixa etária, ela pode ser vista como um indicador sintético de saúde. Essa taxa pode refletir tanto a saúde das crianças como a dos pais, já que está associada a políticas da área de saúde preventiva e acesso aos serviços de saúde e aspectos da saúde dos pais, principalmente, nutrição, hábitos de vida e informações sobre saúde (Noronha et al., 2010). É evidente que essa taxa deixa ser uma boa proxy conforme o lugar (país, região ou estado)

\footnotetext{
${ }^{14}$ Disponível em <www.ipeadata.gov.br>.

${ }^{15}$ A PNAD não foi realizada nos anos de Censo (1991 e 2000) e em 1994. Para estes anos calculamos médias simples dos dados relativos ao ano anterior e posterior.

${ }^{16}$ Disponível em < www.datasus.gov.br>

${ }^{17}$ Os dados sobre TMI têm origem no registro oficial de óbitos, e podem conter problemas de sub-registros, principalmente para as regiões Norte e Nordeste. Contudo, como o que nos interessa é a trajetória da variável, acreditamos que esse problema não afete tanto nossas análises. De qualquer forma foram utilizados dados de menor periodicidade do SIAB, retirados também do DATASUS, que considera indicadores calculados de forma indireta visando corrigir os sub-registros dos óbitos. Nossos resultados para esses dados, considerando taxa de mortalidade infantil, expectativa de vida ao nascer e expectativa de vida aos 60 anos, não alteraram nossas conclusões gerais. Devido à limitação de espaço, esses resultados não serão apresentados, mas estão disponíveis para os interessados.

18 Tocantins foi excluído devido a sua recente criação.
} 
se desenvolve. É o caso dos lugares em que taxa de mortalidade na infância passa a ser bastante baixa, as suas variações não representarão o resultado de grandes mudanças na saúde. Para os estados do Brasil, no período da presente análise, houve uma redução expressiva da taxa de mortalidade na infância, reflexo em grande parte de melhorias na saúde da população brasileira. Isso leva a assumir que essa taxa é uma proxy adequada para a análise que se segue na próxima seção. Contudo, sempre haverá limitações dado o conceito multidimensional de saúde.

\subsection{Teste de Raiz Unitária para Dados em Painel}

Semelhante ao que ocorre nos estudos de séries de tempo, a presença de raiz unitária em dados em painel pode levar uma relação econométrica estimada a ser espúria. Por isso, antes de se aplicar os testes de causalidade, deve-se verificar se as séries utilizadas no presente estudo contêm raiz unitária.

O uso de teste de raiz unitária em painel é recente, porém, os testes encontrados na literatura podem ser classificados em dois grupos. $\mathrm{O}$ primeiro incorpora aqueles testes que assumem a existência de um processo de raiz unitária comum, tal que os parâmetros para persistência para cada unidade (ou grupo) possuem a mesma estrutura autorregressiva (AR (1)), além de permitir a existência do efeito individual. Integram esse grupo os testes propostos por Levin et al. (2002) e o de Breitung (2000), e podem ser considerados como sendo um teste de Dickey-Fuller Aumentado (ADF) com dados agrupados. A hipótese nula é a de que cada série do painel seja integrada de ordem um, contra a hipótese em que todas as séries sejam estacionárias.

O segundo grupo incorpora os testes que permitem a existência de um processo individual de raiz unitária de forma que os parâmetros de persistência podem variar livremente para cada unidade (grupo). Por isso os testes são construídos a partir das estatísticas individuais. Por exemplo, a estatística de teste proposta por Im et al. (2003) é o resultado de uma média das $t$-estatísticas de Dickey-Fuller sobre cada unidade do painel, em que a hipótese nula assume que todas as séries são não estacionárias, ao passo que, na hipótese alternativa pelo menos uma série é estacionária. Esse teste adquire a estrutura do $\mathrm{ADF}$ ao permitir que as defasagens para a variável dependente 
possam ser inseridas, o que possibilita a autocorrelação do erro para cada série. Já os testes ADF-Fisher e o PP-Fisher (Baltagi, 2005) não levam em conta as $t$-estatísticas, mas deriva da combinação dos valores $p$ de cada teste de raiz unitária individual.

\subsection{Teste de Causalidade Proposto por Holtz-Eakin et al. (1988)}

Para o entendimento do teste de causalidade proposto por HoltzEakin et al. (1988) considere o seguinte sistema conhecido na literatura como panel vector auto-regression (PVAR):

$$
\begin{aligned}
& Y_{i t}=\alpha_{1}+\sum_{k=1}^{K} \gamma_{1}^{k} Y_{i t-k}+\sum_{k=1}^{K} \beta_{1}^{k} X_{i t-k}+\eta_{1 i}+\varepsilon_{i t} \\
& X_{i t}=\alpha_{2}+\sum_{k=1}^{K} \beta_{2}^{k} X_{i t-k}+\sum_{k=1}^{K} \gamma_{2}^{k} Y_{i t-k}+\eta_{2 i}+\varepsilon_{i t}
\end{aligned}
$$

Nas Equações (1) e (2), $Y_{i t}$ representa, por exemplo, uma medida de renda do estado $i$ no ano $t, X_{i t}$ é uma medida de saúde no estado $i$ no ano $t, \alpha_{1}$ e $\alpha_{2}$ são termos de intercepto comuns aos estados, $\eta_{1 i}$ e $\eta_{2 i}$ são efeitos fixos que captam a heterogeneidade individual dos estados e são constantes ao longo do tempo, e $k$ denota a defasagem que varia de 1 até $K$.

Com relação à hipótese de causalidade de Granger, no teste de Holtz-Eakin et al. (1988) ela é verificada a partir do teste de Wald. Trata-se de um teste de restrições aplicado aos parâmetros do modelo estimado. Assim, haverá causalidade no sentido de Granger unidirecional de $X$ para $Y$ se nem todos os $\beta_{1 i}$ 's forem iguais a zero em (1), mas todos $\gamma_{2 t}$ 's forem iguais a zero em (2). De forma oposta, haverá causalidade no sentido de Granger unidirecional de $Y$ para $X$ se todos os $\beta_{1 i}$ 's forem iguais a zero em (1), porém nem todos os $\gamma_{2 t}$ 's forem iguais a zero em (2). Pode haver causalidade de Granger bidirecional entre $X$ e $Y$ se nem todos os $\beta_{1 i}$ 's e nem todos os $\gamma_{2 t}$ 's forem iguais a zero. Por fim, podem ocorrer situações em que não há causalidade de Granger entre $X$ e $Y$, para isso, basta que os $\beta_{1 i}$ 's e todos os $\gamma_{2 t}$ 's sejam iguais a zero.Para estimar as Equações (1) e (2) será utilizado o Método dos Momentos Generalizados (GMM) para um painel dinâmico proposto por Arellano e Bond (1991). Esse método estima as equações em primeiras diferenças e, nesse caso, o 
termo de erro é correlacionado com variável dependente defasada. Para contornar esse problema, este método utiliza os valores defasados das variáveis em nível como instrumentos para as diferenças. Além do problema da variável dependente defasada, deve ser levado em conta a endogeneidade da variável explicativa. Por exemplo, se a renda é a variável dependente, possivelmente a variável explicativa saúde é endógena.

A metodologia de Arellano e Bond (1991) também permite enfrentar esse problema da mesma forma que o da variável dependente defasada, ou seja, instrumentalizando as diferenças pelas variáveis defasadas em nível, forma esta que utilizaremos nas nossas estimações. O estimador a ser utilizado é o GMM na versão one-step, já que tem sido observado em diversos estudos que o estimador de GMM two-step, os desvios padrão tendem a serem viesados para baixo em pequenas amostras.

Por fim, a escolha no número de defasagens merece atenção. Alguns trabalhos utilizam métodos tradicionais em séries de tempo como critério de Akaike e Schwartz para a escolha das defasagens. Contudo, como o presente trabalho está mais preocupado em analisar se a variável X é capaz de ajudar na previsão de $\mathrm{Y}$, e vice-versa, independente de um número específico de defasagens, utilizar-se-á um critério arbitrário, mas flexível, como feito por Rocha e Nakane (2007) e Hurlin e Venet (2008). No caso do presente trabalho, será testada causalidade, considerando a estrutura de uma a cinco defasagens.

Esse teste será aplicado para amostra completa dos estados do Brasil no período de 1981-2007. Entretanto, para dar robustez aos resultados, este trabalho também testa a causalidade entre renda e saúde, controlando as possíveis diferenças dessa relação no Brasil. Como em Chen (2008) e Erdil e Yetkiner (2009), que separam suas amostras por nível de renda, separou-se a amostra dos estados do Brasil da seguinte forma: estados do Centro-Sul e estados do Norte-Nordeste. Assim, além de estar captando questões regionais separam-se os estados de maior e menor renda. Esse procedimento se mostra adequado, tendo em vista que ao considerar a renda em 2007, os 15 estados mais pobres todos pertenciam às regiões Norte e Nordeste. 


\subsection{Teste de Causalidade Proposto por Granger e Huang (1997)}

O procedimento que Granger e Huang (1997) apresentaram para testar causalidade para um painel de dados tem como base os fundamentos empregados nos modelos de séries de tempo para fazer comparações entre modelos a partir de suas previsões. Como num painel de dados existe a dimensão para o tempo $(t)$ e dimensão cross-section (i), as previsões ao serem geradas precisam levar em consideração essa estrutura. No teste podem ser usadas as previsões "pós-amostra" e as "fora da amostra". Como a base do teste está nessas previsões, antes de descrevermos o teste vamos apresentar como elas são geradas e os erros calculados a partir delas.

Para gerar as "previsões fora da amostra" o procedimento sugerido é inicialmente retirar uma unidade seccional da amostra, neste caso um dos estados que será denotado por unidade fora da amostra. Os demais estados constituem o que se chama de unidades dentro da amostra e são empregados para estimar o modelo, por exemplo, a Equação (1). A partir do modelo estimado realizam-se as previsões "fora da amostra".

Em seguida, geram-se os erros de previsão para esse estado. Esse procedimento é realizado para todas as demais unidades de forma que ao final são gerados erros de previsões para todos os estados, permitindo a construção de um painel de dados com os erros de previsão.

Para gerar as "previsões pós-amostra", sugere-se usar todas as unidades seccionais, porém, recomenda-se a exclusão $T$ períodos ao final da amostra de uma das unidades seccionais. Com o modelo ajustado, realizam-se as previsões pós-amostra para essa unidade excluída, a qual permitirá gerar os erros de previsão pós-amostra. Contudo, como em Granger e Huang (1997), dá-se preferência aos erros gerados fora da amostra, apresentando apenas resultados para este caso.

Já para avaliar se $X_{i t}$ causa $Y_{i t}$ segundo o procedimento de Granger e Huang (1997), precisa-se estimar de maneira consistente os parâmetros do modelo estrutural (1) e, em seguida, realizar previsões fora da amostra dos erros para Equação (1) e fazer o mesmo procedimento para uma versão modificada pela exclusão das defasagens de $X_{i t}$, Equação (3): 


$$
\begin{aligned}
& Y_{i t}=\alpha_{1}+\sum_{k=1}^{K} \gamma_{1}^{k} Y_{i t-k}+\sum_{k=1}^{K} \beta_{1}^{k} X_{i t-k}+\eta_{1 i}+\varepsilon_{i t} \\
& Y_{i t}=\alpha_{1}+\sum_{\mathrm{k}=1}^{\mathrm{K}} \gamma_{1}^{\mathrm{k}} \mathrm{Y}_{\mathrm{it}-\mathrm{k}}+\eta_{1 \mathrm{i}}+\varepsilon_{\mathrm{it}}
\end{aligned}
$$

Comparando os dois Modelos (1) e (3), se $X_{i t}$ não causa $Y_{i t}$ espera-se que as previsões produzidas por ambos sejam similares. Definindo $e^{1}{ }_{i t}$ e $e^{2}{ }_{i t}$ como erros de previsão fora da amostra gerados respectivamente pelos Modelos (1) e (3). Neste caso, usando a definição proposta por Granger (1969), observa-se que a variância do erro de previsão do Modelo (1) seria igual ou maior que a variância do erro de previsão do Modelo (3). Ou seja:

$$
E\left[\left(e^{1}{ }_{i t}\right)^{2} \geq\left(e^{2}{ }_{i t}\right)^{2}\right]
$$

Para fins de comparação entre os dois modelos Granger e Huang (1997), sugere-se usar o método soma-diferenças. Para tanto, considere a soma e subtração dos erros de previsão dados por:

$$
\begin{aligned}
& S \equiv S U M_{i t}=e_{i t}^{1}+e_{i t}^{2} \\
& D \equiv D I F_{i t}=e_{i t}^{1}-e_{i t}^{2}
\end{aligned}
$$

Para testar a proposição descrita pela Equação (4), recomenda-se, primeiramente, estimar a regressão a seguir:

$$
S_{i t}=a+b D_{i t}+v_{i t}
$$

Em seguida testa-se se o coeficiente $b$ é igual ou maior do que zero por meio da estatística $t$. A rejeição dessa hipótese implica que a variável $X_{i t}$ causa a variável $Y_{i t}$ no sentido de Granger.

O método empregado para estimar os parâmetros da Equação (7) deve envolver o controle e não a estimação dos efeitos fixos e da constante. Análogo ao que foi sugerido por Rocha e Nakane (2007) será utilizado um estimador de primeiras diferenças para estimar a Equação (7), de forma a obter estimativas consistentes de $b$. Já o método de estimação para Equações (1) e (3) será análogo ao da seção anterior. Ou seja, será utilizado o estimador GMM para painel dinâmico proposto por Arellano e Bond (1991). 
Este teste será aplicado para amostra completa de estados do Brasil e para os dois grupos de estados: renda mais alta (Centro-Sul) e de renda mais baixa (Norte-Nordeste).

\subsection{Teste de Causalidade Proposto por Hurlin (2005, 2007)}

Hurlin $(2005,2007)$ propõe um teste de causalidade em um painel de dados heterogêneo com coeficientes fixos. Considere o modelo autorregressivo a seguir com $T$ períodos, e $N$ unidade cross-section:

$$
Y_{i, t}=\alpha_{i}+\sum_{k=1}^{K} \gamma_{i}^{k} Y_{i, t-k}+\sum_{k=1}^{K} \beta_{i}^{(k)} X_{i, t-k}+v_{i, t}
$$

onde $K \in N, \gamma_{i}=\left[\gamma_{i}{ }^{(1)}, \ldots, \gamma_{i}{ }^{(K)}\right]^{\prime}$ e $\beta_{i}=\left[\beta_{i}{ }^{(1)}, \ldots, \beta_{i}{ }^{(K)}\right]^{\prime}$. Os efeitos individuais são assumidos como fixos. As defasagens de ordem $K$ são iguais entre todos os estados, no caso deste trabalho será testada de uma a cinco. Já os parâmetros autorregressivos $\gamma_{i}^{(k)}$ e os coeficientes de inclinação da regressão $\beta_{i}^{(k)}$ diferem entre as unidades individuais, porém, assume-se que esses parâmetros são fixos, ou seja, esse é um modelo de efeitos fixos.

A hipótese nula do teste é de que não há relação causal para todos os estados do painel. Esta é chamada de Hipótese de Não Causalidade Homogênea (HNC), dada por:

$$
H_{0}: \beta_{i}=0 \forall_{i}=1, \ldots N
$$

A hipótese alternativa é a Hipótese de Não Causalidade Heterogênea (HENC), em que se assume que há dois subgrupos das unidades, um com relação causal de $X$ para $Y$, mas não necessariamente com o mesmo processo gerador de dados (DGP) e outro subgrupo onde não há relação causal de $X$ para $Y$. Por exemplo, a HENC na Equação (8) se dá através do coeficiente $\beta_{i}^{(k)}$ ser igual a zero para alguns estados (i), mas diferente de zero para outros. Assim, a HENC é dada por:

$$
\begin{aligned}
H_{1}: & \beta_{i}=0 \forall_{i}=1, \ldots, N_{1} \\
\beta_{i} & \neq 0 \quad \forall_{i}=N_{1}+1, N_{1}+2, \ldots, N
\end{aligned}
$$

Onde $N_{1}$ é desconhecido, mas satisfaz a condição $0 \leq N_{1} / N<1$. 
Portanto, diferente do teste proposto por Holtz-Eakin et al. (1988), em que a hipótese alternativa há causalidade para todos indivíduos com o mesmo processo gerador de dados, a HENC permite duas fontes de heterogeneidade: uma da DGP e outra das relações causais heterogêneas.

Hurlin $(2005,2007)$ propõe um teste estatístico que é a média de estatística Wald individual de não causalidade entre todas as $\mathrm{N}$ unidades. O teste segue a ideia do teste de raiz unitária proposto por Im et al. (2003). A estatística Wald individual associada com a hipótese nula HNC é dada por:

$$
W_{N, T}=\left(\frac{1}{N}\right) \sum_{i=1}^{N} W_{i, T}
$$

Onde $W_{i, T}$ denota a estatística Wald individual do estado $i$ sob: $H_{0}: \beta_{i}=0$. Sob a hipótese de não causalidade, cada estatística Wald individual converge assintoticamente a uma distribuição Quiquadrado com $K$ graus de liberdade.

Sob a hipótese de independência cross-section, as $\mathrm{N}$ estatísticas individuais Wald são independentes. A média cross-section $W_{N, T}^{H}{ }^{c}$ converge a uma distribuição normal quando $\mathrm{T}$ tende a infinito e então $\mathrm{N}$ tende a infinito. E assim, a estatística padronizada referente à pode ser obtida pela seguinte fórmula:

$$
Z_{N, T}=\sqrt{\frac{N}{2 K}}\left(W_{N, T}^{H n c}-K\right) \underset{T, N \rightarrow \infty}{\longrightarrow} d N(0,1)
$$

Para um T fixo a estatística Wald individual $\left(W_{i, T}\right)$ não converge a uma distribuição Qui-quadrado. Hurlin $(2005,2007)$ propõe aproximar os dois primeiros momentos da distribuição desconhecida de $W_{i, T}$ pelos dois primeiros momentos de uma distribuição Fisher. Dado essa aproximação, e $\mathrm{T}>5+2 \mathrm{~K}$, uma estatística padronizada semiassintótica pode ser calculada através da seguinte fórmula:

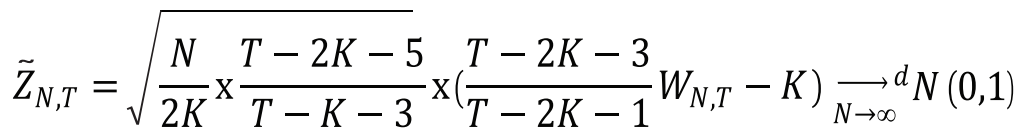


Contudo, quando a amostra tem $\mathrm{T}$ e $\mathrm{N}$ pequenos, a estatística média, e a estatística padronizada têm uma distribuição nula da amostra finita que pode diferir de sua respectiva distribuição assintótica. E assim, aplicando a abordagem proposta por Im et al. (2003), Hurlin $(2005,2007)$ sugere calcular o valor crítico aproximado para $\tilde{Z}_{N, T}$, para um painel finito com $T$ e $N$ fixos, através da seguinte fórmula:

$c_{N, T}(\alpha)=z_{\alpha} \times \frac{T-2 K-1}{T-K-3} \times \sqrt{\frac{2 K(T-K-3)}{N(T-2 K-5)}}+\frac{K(T-2 K-1)}{T-2 K-3}$

Assim, como nos demais casos, este teste será aplicado para os estados do Brasil no período de 1981-2007 e na separação nos dois grupos de estados. ${ }^{19} \mathrm{Na}$ próxima seção serão apresentados os resultados para os três testes. Tal procedimento visa mostrar que há diferenças nos resultados se não considerarmos a possibilidade de heterogeneidade entre os Estados brasileiros. Por essa razão é que as principais conclusões desse estudo serão baseadas no teste de Hurlin (2005, 2007), que traz uma hipótese mais realista da heterogeneidade dos parâmetros do modelo.

\section{Análise dos Resultados}

Esta seção primeiramente analisa correlações entre renda e saúde e posteriormente analisa os resultados dos três diferentes testes de causalidade aplicados para um painel de dados com estados do Brasil no período de 1981 a 2007.

\subsection{Correlações entre Renda e Saúde}

Como foi explicado na segunda seção deste trabalho, espera-se uma relação positiva entre renda e saúde. Essa relação se dá através da causalidade da renda sobre a saúde - uma maior renda dos estados, e assim de sua população, traz a possibilidade das pessoas adquirirem bens e serviços ligados à saúde e também permite o estado

${ }^{19}$ Apesar de termos criados nosso próprio do-file para aplicação desse teste, nós agradecemos os autores dos trabalhos Hurlin e Venet (2008) e Bebczuk et al. (2010) por terem enviado seus códigos do teste utilizados nos seus respectivos trabalhos. 
investir em serviços públicos que afetem a saúde da população - e da causalidade da saúde sobre a renda - uma melhor saúde afeta a renda diretamente através de aumentos da produtividade e indiretamente através de maior acumulação de capital humano e físico e de reduções na taxa de fecundidade. Portanto, espera-se uma relação negativa entre taxa de mortalidade na infância e renda.

A Tabela 1, no Anexo, mostra que a maioria dos estados apresenta os coeficientes de correlação como o esperado e estatisticamente diferente de zero. Por exemplo, Santa Catarina, Rio Grande do Sul e Sergipe têm os seguintes coeficientes de correlação: $-0,83$; $-0,71$ e $-0,68$. Contudo, todos os estados da região Norte apresentam coeficientes positivos de correlação entre renda e taxa de mortalidade na infância, ou seja, o contrário do esperado, e para o Acre, Amapá e Pará esses coeficientes são estatisticamente insignificantes. Apesar desses casos da região Norte, quase todos os demais estados apresentam uma relação positiva e significativa entre renda e saúde.

\subsection{Análise dos Resultados dos Testes de Causalidade}

Através de um painel de dados para os estados do Brasil, no período de 1981-2007, esta seção analisa primeiramente se as séries renda domiciliar per capita (renda) e taxa de mortalidade na infância (TMI) são estacionárias. A Tabela 2, no Anexo, apresenta os resultados dos testes para raiz unitária em três versões: com intercepto individual; com tendência e intercepto individuais e sem tendência e sem intercepto. Como pode ser observado, quando os efeitos fixos são controlados, com exceção do teste de Breitung, que assume uma hipótese forte de homogeneidade nos parâmetros autorregressivos dos estados, todos os demais testes, os que levem em conta a heterogeneidade dos parâmetros e também o teste de Levin et al. (2002), mostram que a $10 \%$ de significância, pode-se rejeitar a hipótese nula de que as séries possuem raiz unitária. Portanto, as séries renda e TMI podem ser consideradas estacionárias. Esse resultado permite inferir que não há necessidade de realizar testes de cointegracão para estimar o modelo.

Já a Tabela 3 mostra os resultados do teste de causalidade de HoltzEakin et al. (1988) entre renda e saúde, para o Brasil, para os grupos de estado de renda mais alta (Centro-Sul) e de renda mais baixa 
(Norte-Nordeste). Observa-se que no nível significância de 10\%, para todas as cinco defasagens, há bi-causalidade entre renda e saúde para o Brasil. Essa análise modifica-se um pouco ao analisar os dois grupos de estados. Para o Centro-Sul há causalidade unidirecional da saúde sobre a renda para as duas primeiras defasagens, contudo, há bi-causalidade para as demais defasagens. Esse resultado poderia implicar que a renda tem um efeito defasado em três anos sobre a saúde. Já para o Norte-Nordeste os resultados apontam não causalidade para a primeira defasagem e bi-causalidade para as demais.

Em geral os resultados do teste de Holtz-Eakin et al. (1988) mostram que a relação entre renda e saúde pode ser considerada bicausal. Estes resultados estão de acordo com a teoria previamente explicada neste trabalho e com resultados empíricos de Chen (2008) e Erdil e Yetkiner (2009), em suas amostras com países. Essa relação também pode dar explicações empíricas para modelos teóricos de múltiplos equilíbrios como os de Chen (2008) e Chakraborty (2004), que sugerem que uma curta expectativa de vida traz um desincentivo à poupança, e, assim, reflete em baixa renda e, de maneira simultânea, lugares com baixa renda (e nível alto de pobreza), com baixo nível inicial de capital, acabam tendo a população com baixa expectativa de vida, ou seja, esses lugares se encontram numa armadilha. Portanto, da relação bi-causal pode surgir a armadilha da pobreza, onde os estados têm baixa renda (e alta pobreza) porque possuem população com saúde precária, e possuem população com saúde precária porque tem baixa renda (alta pobreza), ou seja, um mecanismo de autorreforço da pobreza. Contudo, ao se interpretar esses resultados deve-se lembrar da hipótese de homogeneidade dos parâmetros como uma limitação do teste de Holtz-Eakin et al. (1988).

A Tabela 4 apresenta o teste de causalidade de Granger e Huang (1997) entre renda e saúde para o Brasil, Centro-Sul e NorteNordeste. Notam-se resultados bem diferentes dos apresentados no teste proposto por Holtz-Eakin et al. (1988). No Brasil, considerando uma defasagem e nível de significância de $10 \%$, os resultados mostram uma relação bi-causal. Contudo, para três, quatro e cinco defasagens a causalidade é unidirecional na direção da renda para a saúde. Resultados de causalidade nesta direção são encontrados em Erdil e Yetkiner (2009) para alguns países do grupo de renda baixa e de renda média. Porém, esses resultados não se mantêm ao 
analisar os estados separados em grupos. Para o Centro-Sul, o teste aponta causalidade unidirecional da saúde sobre a renda para as três primeiras defasagens e causalidade no sentido contrário para cinco defasagens, mostrando nesse caso que a causalidade é melhor explicada na direção da saúde sobre a renda. Para o Norte-Nordeste há causalidade no sentido da renda sobre a saúde apenas para quatro defasagens e não causalidade para as demais defasagens.

O resultado para este último caso, não causalidade, pode estar sendo influenciado pelo diferente padrão apresentado entre essas duas regiões. Como foi observado anteriormente na análise de correlações, os coeficientes para a região Norte se apresentam ao contrário do esperado. E assim, a homogeneidade nos parâmetros, assumida no teste de Granger e Huang (1997), principalmente neste caso, pode implicar resultados enganosos. Para dar robustez aos resultados, a Tabela 5 apresenta resultados para cada uma dessas regióes. Observase uma mudança brusca dos resultados para a região Nordeste com causalidade no sentido da saúde sobre a renda para uma, duas, quatro e cinco defasagens e não causalidade para três defasagens, ou seja, mostrando que esse teste aponta que nessa região saúde causa renda. Já para região Norte, há causalidade unidirecional da saúde sobre a renda para uma e quatro defasagens, relação bi-causal para duas defasagens e não causalidade para as demais. Portanto, os diferentes resultados apresentados nessa divisão das regiões mostra que a homogeneidade dos parâmetros, quando estes são heterogêneos, influencia fortemente as conclusões.

Nos testes realizados até aqui, considerou-se que ao separar a amostra, os estados de um mesmo grupo dessa divisão têm o mesmo padrão de causalidade e mesmos parâmetros do modelo, mas que esse padrão e os parâmetros podem ser diferentes dos demais grupos e da amostra total. Já a Tabela 6 analisa os resultados obtidos com o teste de causalidade proposto por Hurlin $(2005,2007)$, que controla a heterogeneidade na causalidade entre os estados. Ou seja, diferente dos testes anteriores que consideram o mesmo modelo dinâmico para todas as unidades, esse teste apresenta um modelo com diferentes parâmetros para os estados, tanto no que se refere à estrutura autorregressiva como ao parâmetro de inclinação.

Portanto, neste teste a heterogeneidade entre os estados é considerada até mesmo dentro de um mesmo grupo. Diante das diferentes 
relações entre renda e saúde apresentada pelos estados do Brasil, como as particularidades dos estados da região Norte, principalmente, os resultados do teste proposto por Holtz-Eakin et al. (1988), que considera homogeneidade dos parâmetros no modelo e ajuste dentro da amostra, podem ser enganosos. Se os parâmetros do nosso Modelo (8) são heterogêneos, a estimação assumindo homogeneidade incorre em viés (Pesaran; Smith, 1995). Assim, a análise feita a partir do teste proposto por Hurlin $(2005,2007)$ pode trazer resultados mais confiáveis, e, consequentemente, nossa conclusão principal se baseará neste teste.

Considerada a estatística padronizada semiassintótica $\left(\tilde{Z}_{N, T}\right)$, os resultados da Tabela 6 mostram uma relação de causalidade unidirecional da renda sobre a saúde para as três primeiras defasagens e bi-causalidade para as duas últimas no Brasil. Ao considerar os valores críticos corrigidos para uma amostra com $\mathrm{T}$ e $\mathrm{N}$ fixos $\left(\mathrm{C}_{N, T}\right)$, há causalidade unidirecional da saúde sobre a renda para as quatro primeiras defasagens e não causalidade para cinco defasagens. Para o Centro-Sul do país, ao considerar a estatística semiassintótica, os resultados são os mesmo que para o Brasil, já para os valores críticos corrigidos para uma amostra com $\mathrm{T}$ e $\mathrm{N}$ pequenos, há causalidade unidirecional da saúde sobre a renda para as duas primeiras defasagens e não causalidade para as demais. Por fim, para os estados do Norte-Nordeste a estatística padronizada semiassintótica mostra o mesmo padrão do que para o Brasil e para o Centro-Sul, já para os valores críticos corrigidos para uma amostra com $\mathrm{T}$ e $\mathrm{N}$ fixos, há causalidade unidirecional da saúde sobre a renda para uma, três e quatro defasagens e não causalidade para os demais.

Portanto, a análise através do teste proposto por Hurlin (2005, 2007) mostra que para o Brasil, para os grupos de estados de renda mais alta (Centro-Sul) e para os de renda mais baixa (Norte-Nordeste), as evidências são mais claras no sentido causalidade da saúde em direção à renda. Utilizando esse mesmo método, Chen (2008) encontra uma relação bi-causal para amostra completa e para os países de renda média, e não causalidade para os países de renda baixa, ou seja, para o mesmo método os resultados de causalidade entre renda e saúde são diferentes dos encontrados no presente trabalho. Para dar mais robustez a essas conclusões, esse teste ainda foi aplicado considerando alguns outros casos. Por limitação de espaço, os resultados não serão apresentados aqui, mas podem ser obtidos junto aos 
autores. Primeiramente, pode ser argumentado que alguma variável explicativa, não constante no tempo, não foi incluída no modelo e que as estimações são viesadas. Para controlar esse argumento, pelo menos em parte, inserimos tendência linear individual nas estimações como proxy das variáveis omitidas. Em segundo lugar, dado o conceito multidimensional de saúde, nossa proxy pode estar afetando os resultados. Para tentar controlar em parte esse argumento, foram utilizados alguns indicadores de mortalidade proporcional, segundo as seguintes causas de doenças: afecções no período perinatal, infecciosas e parasitárias, causas mal definidas, aparelho circulatório, neoplasmas e diabetes. As três primeiras estão relacionadas a condições socioeconômicas precárias, já que estão ligadas a menor acesso a serviços de saúde, e as duas primeiras são tidas como mortes por causas evitáveis, as três últimas estão relacionadas ao envelhecimento populacional e positivamente associadas à melhor qualidade de vida e ao acesso a melhores serviços de saúde (Noronha et al. (2010)).

Todos os resultados mostraram que a causalidade é mais bem explicada no sentido da saúde para a renda. Resultados de causalidade nesse sentido dão suporte à teoria que mostra que melhoras na saúde têm papel importante para a renda. Brinkley (2003) encontra causalidade nesse mesmo sentido usando séries de tempo de dados agregados para os EUA.

Outra forma para dar robustez aos nossos resultados é apresentada na Tabela 7, que mostra a escolha de defasagens com base em um critério mais formal, neste caso o de Schwarz que também é utilizado em Hartwig (2010). Pode ser observado que as conclusões da direção da causalidade encontradas anteriormente não são modificadas.

As formas de se pensar nesse sentido da causalidade, como dito anteriormente, podem ser tanto através dos efeitos diretos como dos indiretos. Pode ser discutido que a saúde pode ter influenciado a produtividade média e oferta de trabalho nos estados do Brasil. Mas também deve ser destacado o possível papel que a melhor saúde implicou incentivar o investimento em educação, dado que uma maior possibilidade de mortalidade diminui o retorno desse investimento, pensamento análogo para o investimento em capital físico. E ainda, dada que uma menor fecundidade implica maior renda per capita, reduções da mortalidade nos estados do Brasil podem ter afetado a fecundidade, explicação que pode ser vista tanto em termos indivi- 
duais através do trade-off quantidade-qualidade, como pelo fenômeno da transição demográfica, em que reduções na mortalidade acabam em um último estágio sendo seguidas de reduções na fecundidade, que acaba sendo benéfico para a renda de um determinado lugar. Contudo, esses efeitos diretos e indiretos, e seus mecanismos, não são captados no simples modelo bivariado de causalidade analisado aqui.

Portanto, ao se considerar uma estrutura homogênea dos parâmetros nos testes de causalidade, as conclusões podem ser enganosas. No caso deste trabalho, que utiliza uma base de dados com os estados do Brasil, no período de 1981 a 2007, as evidências são mais claras para causalidade no sentido da saúde sobre a renda.

\section{Considerações Finais}

Este trabalho teve o objetivo principal de analisar a relação de causalidade entre renda e saúde, buscando controlar as possíveis diferenças dessa relação ao longo do território brasileiro. Foram aplicados três testes de causalidade no sentido de Granger. O método de Holtz-Eakin et al. (1988) apontou causalidade bidirecional. Já as evidências com o teste de Granger e Huang (1997) foram de causalidade unidirecional da renda sobre a saúde pra o Brasil, causalidade unidirecional da saúde sobre a renda nos estados de renda mais alta (Centro-Sul) e não causalidade para o grupo de estados de renda mais baixa (Norte-Nordeste). No caso do teste proposto por Hurlin $(2005,2007)$, as evidências são mais claras para causalidade no sentido da saúde sobre a renda tanto para o Brasil, como para o grupo de estados de renda mais alta e o de renda mais baixa.

Relação bidirecional apresentada no teste de Holtz-Eakin et al. (1988) está de acordo com resultados gerais encontrados em Chen (2008) e Erdil e Yetkiner (2009). Contudo, para o teste que controla a heterogeneidade da relação causal dentro de um mesmo grupo Hurlin $(2005,2007)$ - os resultados mostraram causalidade da saúde sobre a renda. Para a causalidade nessa direção, as políticas públicas seriam mais favoráveis em melhorar a saúde para afetar a renda. Causalidade nessa direção também pode implicar que as políticas públicas com o objetivo de aumentar a renda e reduzir a pobreza através de melhorias na educação, acumulação de capital físico, entre outras 
formas, podem não ter o efeito desejado se a saúde da população não for levada em consideração. Além disso, dada a heterogeneidade entre os estados, a eficiência e efetividade de políticas de saúde para afetar a renda podem diferir entre os estados.

Portanto, a não consideração da heterogeneidade da causalidade pode trazer resultados enganosos, como no caso do presente trabalho a conclusão de uma relação bi-causal entre renda e saúde apontada pelo teste de Holtz-Eakin et al. (1988), ou relação unidirecional da renda sobre a saúde apontada na amostra completa dos estados do Brasil no teste de Granger e Huang (1997). Contudo, deve-se tomar cuidado ao interpretar os resultados. Por exemplo, a não causalidade da renda sobre a saúde apresentada no teste de causalidade proposto por Hurlin $(2005,2007)$ não significa que a renda não tenha efeito sobre a saúde. Indica apenas que se tal relação existe, ela não pode ser identificada neste teste bivariado que segue a abordagem de causalidade no sentido de Granger.

Os trabalhos futuros podem incorporar alguns refinamentos para compreender melhor essa relação entre saúde e renda. Para o teste de causalidade proposto por Hurlin $(2005,2007)$ os momentos exatos da estatística Wald individual poderiam ser estimados com o uso de um bootstrapping. O uso de microdados e testes que permitissem mensurar o efeito da saúde sobre a renda e vice-versa poderiam ser relevantes, já que causalidade poderia levar a conclusões diferentes se a magnitude dos efeitos for pequena. Nesse caso, entender o papel de fatores indiretos como, por exemplo, a educação, nessa relação é de fundamental importância. Por fim, como extensão deve ser ressaltada a importância de analisar especificamente os benefícios de políticas públicas na relação entre renda e saúde.

\section{Referências}

Adams, P.; Hurd, M. D.; Mcfadden, D.; Merrill, A.; Ribeiro, T. "Healthy, Wealthy and Wise? Tests for Direct Causal Paths between Health and Socioeconomic Status", Journal of Econometrics, 112, pp. 3-56, 2003.

Alderman, H.; Behrman, J.; Lavy, V.; Menon, R. Child nutrition, child health and school enrollment: a longitudinal analysis. Washington: The World Bank Policy Research Department, Jan. 1997 (Policy Research Working Paper, n. 1.700).

Almeida, C., Travassos, C., Porto, S., Labra, M.E.A. Health sector reform in Brazil: a case study of inequity. International Journal of Health Services, Farmingdale, NY, v.30, n.1, p.129-162, 2000. 
Alves, L.F.E.; Andrade, M.V. Impactos da saúde nos rendimentos individuais no Brasil. Revista de Economia Aplicada, v.7, n.2, p.359-388, 2003.

Alves, D., Beluzzo, W. Infant mortality and child health in Brazil. Economics and Human Biology, v.2, n. 3, p.391-410, 2004.

Arellano, M. \& Bond, S. Some tests of specification for panel data: Monte Carlo evidence and an application to employment equations, Review of Economic Studies, v. 58, p. 277-297, 1991.

Baltagi, Badi, H. Econometric Analysis of Panel Data. England: John Wiley \& Sons, Thild edition, 2005.

Bebczuk, R.; Burdisso, T.; Carrera, J.; Sangiácomo, M. (2010). A new look into credit procyclicality: International panel evidence. BIS CCA Conference, 2010.

Bloom, D. E.; Canning, D. And Sevilla, J. The Effect of Health on Economic Growth: A Production Function Approach. World Development, v. 32, n.1, p. 1-13, 2004.

Bloom, D. E.; Canning, D. Health and Economic Growth: Reconciling the Micro and Macro Evidence, CDDRL Working Papers, Stanford University, 2005.

Breitung, J. The local power of some unit root tests for panel data. Advances in Econometrics, Volume 15: Nonstationary Panels, Panel Cointegration, and Dynamic Panels, ed. B. H. Baltagi, 161-178. Amsterdam: JAY Press, 2000.

Brinkley G. L. The macroeconomic impact of improving health: investigating the causal direction. UC Davis, mimeo, 2003.

Camelo, R. S.; Tavares, P. A.; Saiani, C.C.S. Alimentação, nutrição e saúde em programas de transferência de renda: evidências para o Programa Bolsa Família. Encontro Nacional de Economia, Anpec, 2009.

Case, A.; Lubotsky, D.; N.; Paxson, C. Economic Status and Health in Childhood: The origins of Gradient. American Economic Review, v. 92, p.1308-1334, 2002.

Chakraborty, S. Endogenous Lifetime and Economic Growth. Journal of Economic Theory, v. 116, p. 119-37, 2004.

Chen, W. Three essays on the health and wealth of nations. PhD dissertation, University of Victoria, 2008.

Crespo, A.; Reis, M. Child health, household income and the local public provision of health care in Brazil. 2008. Mimeografado.

Devlin, N.; Hansen, P. Health Care Spending and Economic Output: Granger Causality, Applied Economics Letters, v. 8, p.561-64, 2001

Erdil, E.; Yetkiner, I. H. The Granger-causality between health care expenditure and output: a panel approach. Applied Economics, v. 41, n.4, p. 511-518, 2009.

Granger, C. W. J. Investigating causal relationships by econometric models and cross-spectral methods. Econometrica, v. 37, p. 424-438, 1969.

Granger, C. W. J. E Huang, L. Evaluation of Panel Data Models: Some suggestions from Time Series, Mimeo.U.C. San Diego, 1997.

Hartwig, J. Is health capital formation good for long-term economic growth? Panel Granger causality evidence for OECD countries. Journal of macroeconomics, v. 32, $\mathrm{n}^{\mathrm{o}}$ 1, p. 314-325, 2010.

Heckman, J. J. Causal parameters and policy analysis in economics: a twentieth century retrospective. Quarterly Journal of Economics, v. 115, n 1, p. 45-97, 2000.

Heckman, J. J. Econometric causality, Cemmap working paper CWP/08, The institute for fiscal Studies, Department of Economics, UCL, 2008.

Holland, P. W. Statistical and causal inference. Journal of the American Statistical Association, v. 89, p. 197-221, 1986.

Holtz-Eakin, D.; Newey, W. E Rosen, H. S. Estimating vector autoregressions with panel data, Econometrica, vol. 56, pp. 1371-1395, 1988.

Hsiao, C. Analysis of panel data, Cambridge University Press, 2003.

Est. Econ., São Paulo, vol. 42, n.2, p. 229-261, abr.-jun. 2012 
Hurlin, C. Un Test Simple de 1.Hypothèse de Non Causalité dans un Modèle de Panel Hétérogène, Revue Economique, 56(3), 799-809, 2005.

Hurlin, C. Testing for Granger Non Causality in Heterogeneous Panels, Working Paper LEO, Université d.Orléans, 2007-10, 2007.

Hurlin, C.; Venet, B. Financial Development and Growth: a re-examination using a panel Granger causality test, Working Papers No.halshs-00319995_v1, Hyper Article en Ligne, Sciences de l'Homme et de la Société, 2008.

IBGE. Síntese de Indicadores Sociais: Uma análise das condições de vida da população brasileira. IBGE, 2005.

Im, K.S., Pesaran, M.H.; Shin, Y. Testing for Unit Roots in Heterogeneous Panels. Journal of Econometrics, v. 115, p. 53-74, 2003.

Jayachandran, S.; Llera-Muney, A. Life expectancy and human capital investments: Evidence from maternal mortality decline. Quarterly Journal of Economics, v. 124, p. 349-397, 2009.

Kalemli-Ozcan, S., Ryder, H.; Weil, D. Mortality Decline, Human Capital Investment and Economic Growth. Journal of Development Economics, v. 62, p.1-23, 2000.

Kalemli-Ozcan, S. Does Mortality Decline Promote Economic Growth? Journal of Economic Growth, v. 7, p.411-439, 2002.

Kalemli-Ozcan, S. A Stochastic Model of Mortality, Fertility, and Human Capital Investment. Journal of Development Economics, v. 70, p.103-118, 2003.

Kassouf, A. L. A demanda de saúde infantil no Brasil por região e setor. Pesquisa e Planejamento Econômico, Rio de Janeiro, v. 24, n. 2, dez. 1994.

Knowles, S.; Owen, D.P. Health capital and cross-country variation in income per capita in the MankiwRomer-Weil model. Economics Letters, v.48, p. 99-106, 1995.

Levin, A. Lin, C.F.; Chu, C. S. J. Unit Root Tests in Panel Data: Asymptotic AN Finite sample Properties. Journal of Econometrics, v. 108, p. 1-24, 2002.

Lorentzen, P.; Mcmillan, J. E.; Wacziarg, R. (2008) Death and Development. Journal Economic Growth, v.13, p.81-124.

Machado, D. C. Efeitos da saúde na idade de entrada à escola. Pesquisa e planejamento econômico, v. 38, p. $67-95,2008$.

Macinko, J.; Guanais, F.; Souza, M. F. M. Evaluation of the impact of family health program on infant mortality in Brazil, 1990-2002. Journal of Epidemiology and Community Health, v. 60, p. $13-19,2006$.

Mendonça, M. e Seroa Da Motta, R. Saúde e saneamento no Brasil. Texto para discussão, n. 1081, IPEA, 2005.

Michaud, P.; Van Soest A. "Health and Wealth of Elderly Couples: Causality Tests Using Dynamic Panel Data Models", Rand Labor and Population, Working Paper, wr-191, September 2004.

Monteiro, C. A.; Benicio, M. H.; Konno, S. C.; Silva, A. C. F.; Lima, A. L. L.; Conde, W. L. Causas do declínio da desnutrição infantil no Brasil, 1996-2007. Revista de Saúde Pública, v.43, p.35-43, 2009.

Neri, M.; Soares, W. Desigualdade social e saúde no Brasil. Cadernos de Saúde Pública, v.18, p.77-87, 2002.

Noronha, K; Andrade, M. Social inequality in the Access to health care services in Brazil. LATIN AMERICAN MEETING OF THE ECONOMETRIC SOCIETY, 2002.

Noronha, K.; Figueiredo, L. K.; Andrade, M. V. Health and economic growth among the states of Brazil from 1991 to 2000. Revista Brasileira de Estudos Populacionais, v. 27, p.269-283, 2010.

Pesaran, H. M.; Smith, R. Estimating long-run relationships from dynamic heterogenous panels. Journal of Econometrics, 68, 79-113, 1995.

Posnett, J.; Hitiris, T. The determinants and effects of health expenditure in developed countries. Journal of Health Economics, 11, 173-81, 1992. 
Pritchett, L. and Summers, L. H. Wealthier is Healthier. Journal of Human Resources, v. 31, p 841-68, 1996.

Reis, M.; Crespo, A. O impacto da renda domiciliar sobre a saúde infantil no Brasil. Texto para discussão, n. 1397, IPEA, 2009.

Rocha, B. de P. e Nakane, M. I. Sistema financeiro e desenvolvimento econômico: evidências de causalidade em um painel para o Brasil. XXXV ENCONTRO NACIONAL DE ECONOMIA, Anpec, 2007.

Rubin, D. B. Inference and missing data, Biometrika, v. 63, p. 581-592, 1976.

Rubin, D. B. Statistical and causal inference, Journal of the American Statistical Association, v. 81, p. 945-960, 1986.

Sala-I-Martin, X.; Doppelhofer, G.; Miller R. Determinants of Long-Term Growth: A Bayesian Averaging of Classical Estimates (BACE) Approach. American Economic Review, v. 94, n. 4, p. 813-835, 2004.

Sala-I-Martin, X. Health and Economic Growth Findings and policy implications. In López-Casanova; Guillem; Rivera, Berta; Currais, Luis (eds.): Health and Economic growth: findings and policy implications, 2005.

Schultz, T.P. Wage gains associated with height as a form of health human capital. American Economic Review, v.92, p.349-353, 2002.

Sims, C. A. Money, income and causality. American Economic Review, v. 62, p. 540-552, 1972.

Soares, R. R. Mortality Reductions, Educational Attainment, and Fertility Choice. American Economic Review, v. 95, p. 580-601, 2005.

Soares, R. R. The effect of longevity on schooling and fertility: evidence from the Brazilian Demographic and Health Survey. Journal of Population Economics, v.19, n.1, p. 71-97, n.1, 2006.

Soares, R. R. Health and the Evolution of Welfare across Brazilian Municipalities, Journal of Development Economics, v.84, p. 590-608, 2007.

Weil, D. Accounting for the effect of health on economic growth. The Quarterly Journal of Economics, v. 122 , p. 1265-1306, 2007.

\section{Anexos}

Tabela 1 - Correlações entre Renda e Saúde (TMI), Estados do Brasil, 1981- 2007

\begin{tabular}{|c|c|c|c|c|c|}
\hline UF & corr. & UF & corr. & UF & corr. \\
\hline$A C$ & 0,16 & MA & $0,54^{\star \star *}$ & RJ & $-0,51^{\star \star \star}$ \\
\hline$A L$ & $-0,54^{* * *}$ & $M G$ & $-0,66^{\star \star *}$ & RN & $-0,65^{\star \star \star}$ \\
\hline AM & $0,49^{\star \star}$ & MS & $-0,58^{\star \star \star}$ & RO & $0,35^{\star}$ \\
\hline AP & 0,16 & MT & 0,06 & $\mathrm{RR}$ & $0,42^{\star \star}$ \\
\hline BA & $-0,35^{\star}$ & PA & 0,28 & $\mathrm{RS}$ & $-0,71^{\star \star \star}$ \\
\hline CE & $-0,63^{\star \star \star}$ & PB & $-0,81^{\star \star *}$ & SC & $-0,83^{\star \star \star}$ \\
\hline DF & $-0,69^{\star \star *}$ & PE & $-0,58^{\star \star *}$ & SE & $-0,68^{\star \star \star}$ \\
\hline ES & $-0,43^{\star *}$ & $\mathrm{PI}$ & 0,05 & SP & $-0,35^{\star}$ \\
\hline GO & $-0,53^{\star \star \star}$ & PR & $-0,81^{\star \star \star}$ & & \\
\hline
\end{tabular}

Fonte: Cálculos do autor a partir dos dados do Ipeadata e do DATASUS.

Notas: $* * *$ significante a $1 \%$; ** significante a $5 \%$ e *significante a $10 \%$. 
Tabela 2 - Testes de Raiz Unitária para Renda e Saúde (TMI), Estados do Brasil, 1981-2007

\begin{tabular}{|c|c|c|c|c|c|c|}
\hline \multirow[t]{2}{*}{ Teste } & \multicolumn{2}{|c|}{ Com intercepto individual } & \multicolumn{2}{|c|}{$\begin{array}{c}\text { Com tendência e intercepto } \\
\text { individuais }\end{array}$} & \multicolumn{2}{|c|}{$\begin{array}{l}\text { Sem tendência linear e } \\
\text { sem intercepto }\end{array}$} \\
\hline & Estatística & Prob. ${ }^{(1)}$ & Estatística & Prob. $^{(1)}$ & Estatística & Prob. $^{(1)}$ \\
\hline \multicolumn{7}{|c|}{ Variável: renda } \\
\hline Levin, Lin \& Chu $\mathrm{t}^{(2)}$ & $-3,91$ & 0,00 & $-8,12$ & 0,00 & 5,36 & 1,00 \\
\hline Breitung t-stat ${ }^{(2)}$ & $-7,79$ & 0,00 & 4,17 & 1,00 & $-3,12$ & 0,00 \\
\hline Im, Pesaran, Shin W-stat ${ }^{(3)}$ & $-2,61$ & 0,00 & $-10,28$ & 0,00 & - & - \\
\hline ADF - Fisher Chi-square ${ }^{(3)}$ & 87,62 & 0,00 & 197,71 & 0,00 & 12,01 & 1,00 \\
\hline PP- Fisher Chi-square ${ }^{(3)}$ & 83,83 & 0,00 & 116,59 & 0,00 & 8,76 & 1,00 \\
\hline \multicolumn{7}{|c|}{ Variável: TMI } \\
\hline Levin, Lin \& Chu $t^{(2)}$ & $-9,10$ & 0,00 & $-2,10$ & 0,00 & $-15,93$ & 0,00 \\
\hline Breitung t-stat ${ }^{(2)}$ & 1,79 & 0,96 & 3,54 & 1,00 & 6,99 & 0,00 \\
\hline Im, Pesaran, Shin W-stat ${ }^{(3)}$ & $-3,85$ & 0,00 & $-4,11$ & 0,00 & - & - \\
\hline ADF - Fisher Chi-square ${ }^{(3)}$ & 101,36 & 0,00 & 98,12 & 0,00 & 290,83 & 0,00 \\
\hline PP- Fisher Chi-square ${ }^{(3)}$ & 99,12 & 0,00 & 73,34 & 0,00 & 423,04 & 0,00 \\
\hline
\end{tabular}

Fonte: Cálculos do autor a partir dos dados do Ipeadata e do DATASUS.

Notas: (1) As probabilidades para os testes de Fisher são computadas usando-se uma distribuição assintótica Qui-quadrado. Os demais testes assumem normalidade assintótica. (2) Hipótese nula: raiz unitária (assume processo de raiz unitária comum). (3) Hipótese nula: raiz unitária (assume processo de raiz unitária individual).

Tabela 3 - Teste de Causalidade de Holtz-Eakin et al. (1988) entre Renda e Saúde (TMI) para o Brasil, Centro-Sul e Norte-Nordeste, 1981-2007

\begin{tabular}{|c|c|c|c|c|c|}
\hline Defasagem & $\mathrm{K}=1$ & $K=2$ & $K=3$ & $K=4$ & $K=5$ \\
\hline \multicolumn{6}{|c|}{ Brasil } \\
\hline $\mathrm{TMI} \Rightarrow$ Renda & $4,57^{\star \star}$ & $17,64^{\star \star \star}$ & $14,33^{\star \star \star}$ & $19,56^{\star \star \star}$ & $28,20^{\star \star \star}$ \\
\hline Renda $\Rightarrow \mathrm{TMI}$ & $6,96^{\star \star \star}$ & $10,28^{\star \star *}$ & $25,23^{* \star *}$ & $31,80^{\star \star \star}$ & $58,19^{\star \star \star}$ \\
\hline \multicolumn{6}{|c|}{ Centro-Sul } \\
\hline $\mathrm{TMI} \Rightarrow$ Renda & $38,48^{* * *}$ & $45,21^{\star \star \star}$ & $18,22^{* \star *}$ & $19,75^{\star \star *}$ & $30,44^{\star \star \star}$ \\
\hline Renda $\Rightarrow \mathrm{TMI}$ & 1,00 & 2,80 & $19,99^{\star \star \star}$ & $26,79^{\star \star \star}$ & $35,79^{\star \star \star}$ \\
\hline \multicolumn{6}{|c|}{ Norte-Nordeste } \\
\hline $\mathrm{TMI} \Rightarrow$ Renda & 0,41 & $8,16^{\star *}$ & $15,10^{\star \star \star}$ & $24,13^{\star \star \star}$ & $22,20^{\star \star \star}$ \\
\hline Renda $\Rightarrow$ TMI & 0,57 & $8,63^{\star \star}$ & $7,04^{*}$ & $21,34^{\star \star \star}$ & $19,82^{* \star \star}$ \\
\hline
\end{tabular}

Fonte: Cálculos do autor a partir dos dados do Ipeadata e do DATASUS.

Notas: ${ }^{* * *}$ significante a $1 \%$; ${ }^{* *}$ significante a $5 \%$ e ${ }^{*}$ significante a $10 \%$. 
Tabela 4 - Teste de Causalidade de Granger e Huang (1997) entre Renda e Saúde (TMI) para o Brasil, Centro-Sul e Norte-Nordeste, 1981-2007

\begin{tabular}{|c|c|c|c|c|c|}
\hline Def. & $K=1$ & $\mathrm{~K}=2$ & $K=3$ & $K=4$ & $K=5$ \\
\hline \multicolumn{6}{|c|}{ Brasil } \\
\hline $\mathrm{TMI} \Rightarrow$ Renda & $-3,64^{* \star \star}$ & $-1,07$ & 0,28 & $-0,53$ & 0,42 \\
\hline Renda $\Rightarrow \mathrm{TMI}$ & $-1,67^{\star \star}$ & $-0,38$ & $-1,77^{\star \star}$ & $-1,42^{*}$ & $-1,33^{*}$ \\
\hline \multicolumn{6}{|c|}{ Centro-Sul } \\
\hline $\mathrm{TMI} \Rightarrow$ Renda & $-5,75^{\star \star \star}$ & $-4,07^{\star \star \star}$ & $-1,51^{*}$ & 0,36 & 1,80 \\
\hline Renda $\Rightarrow \mathrm{TMI}$ & $-0,88$ & 1,53 & $-0,24$ & $-0,44$ & $-1,49^{*}$ \\
\hline \multicolumn{6}{|c|}{ Norte-Nordeste } \\
\hline $\mathrm{TMI} \Rightarrow$ Renda & 4,66 & $-0,83$ & 0,01 & $-1,27$ & 0,13 \\
\hline Renda $\Rightarrow$ TMI & $-0,43$ & $-1,06$ & $-1,16$ & $-1,36^{*}$ & $-0,05$ \\
\hline
\end{tabular}

Fonte: Cálculos do autor a partir dos dados do Ipeadata e do DATASUS.

Notas: ${ }^{* * *}$ significante a $1 \%$; ${ }^{* *}$ significante a $5 \%$ e ${ }^{*}$ significante a $10 \%$. Teste unicaudal.

Tabela 5 - Teste de Causalidade de Granger e Huang (1997) entre Renda e Saúde (TMI) para a região Nordeste e Norte, 1981-2007

\begin{tabular}{lccccc}
\hline Defasagem & $\mathrm{K}=1$ & $\mathrm{~K}=2$ & $\mathrm{~K}=3$ & $\mathrm{~K}=4$ & $\mathrm{~K}=5$ \\
\hline Norte & & & & \\
\hline TMI $\Rightarrow$ Renda & $-1,84^{* \star}$ & $-1,90^{* \star}$ & $-0,36$ & $-2,62^{* * \star}$ & $-1,13$ \\
Renda $\Rightarrow$ TMI & 0,70 & $-1,66^{* \star}$ & $-1,21$ & $-1,09$ & $-1,01$ \\
\hline Nordeste & & & & \\
\hline TMI $\Rightarrow$ Renda & $-6,21^{* \star *}$ & $-3,20^{* \star *}$ & $-1,14$ & $-3,02^{* \star *}$ & $-1,61^{*}$ \\
Renda $\Rightarrow$ TMI & 3,61 & 0,76 & 0,12 & $-0,83$ & 0,36 \\
\hline
\end{tabular}

Fonte: Cálculos do autor a partir dos dados do Ipeadata e do DATASUS.

Notas: ${ }^{* * *}$ significante a $1 \% ;{ }^{* *}$ significante a $5 \%$ e *significante a $10 \%$. Teste unicaudal. 
Tabela 6 - Teste de Causalidade de Hurlin $(2005,2007)$ entre Renda e Saúde (TMI), Estados do Brasil, 1981-2007

\begin{tabular}{|c|c|c|c|c|c|}
\hline Defasagem & $K=1$ & $K=2$ & $K=3$ & $K=4$ & $K=5$ \\
\hline \multicolumn{6}{|c|}{ Brasil } \\
\hline \multicolumn{6}{|c|}{$\mathrm{TMI} \Rightarrow$ Renda } \\
\hline$W_{\text {HNC }}$ & 2,94 & 4,97 & 7,07 & 10,41 & 13,75 \\
\hline$\tilde{Z}_{N, T}$ & 5,64 & 5,65 & 5,72 & 7,02 & 7,13 \\
\hline \multicolumn{6}{|c|}{ Renda $\Rightarrow \mathrm{TMI}$} \\
\hline$W_{\text {HNC }}$ & 0,69 & 2,39 & 4,34 & 7,28 & 8,76 \\
\hline$\tilde{Z}_{N, T}$ & $-1,24$ & 0,35 & 1,46 & 3,19 & 2,48 \\
\hline $\mathrm{C}_{\mathrm{N}, \mathrm{T}}(0,1)$ & 1,51 & 2,85 & 4,22 & 5,72 & 7,48 \\
\hline $\mathrm{C}_{\mathrm{N}, \mathrm{T}}(0,05)$ & 1,63 & 3,02 & 4,45 & 6,01 & 7,87 \\
\hline $\mathrm{C}_{\mathrm{N}, \mathrm{T}}(0,01)$ & 1,86 & 3,36 & 4,89 & 6,57 & 8,60 \\
\hline \multicolumn{6}{|c|}{ Centro-Sul } \\
\hline \multicolumn{6}{|c|}{$\mathrm{TMI} \Rightarrow$ Renda } \\
\hline $\mathrm{W}_{\mathrm{HNC}}$ & 4,38 & 6,38 & 6,74 & 9,36 & 13,94 \\
\hline$\tilde{Z}_{N, T}$ & 6,54 & 5,55 & 3,40 & 3,73 & 4,75 \\
\hline \multicolumn{6}{|c|}{ Renda $\Rightarrow$ TMI } \\
\hline$W_{\text {HNC }}$ & 0,54 & 2,07 & 4,86 & 8,01 & 11,61 \\
\hline$\tilde{Z}_{N, T}$ & $-1,10$ & $-0,21$ & 1,49 & 2,66 & 3,34 \\
\hline $\mathrm{C}_{\mathrm{N}, \mathrm{T}}(0,1)$ & 1,74 & 3,18 & 4,66 & 6,28 & 8,22 \\
\hline $\mathrm{C}_{\mathrm{N}, \mathrm{T}}(0,05)$ & 1,92 & 3,45 & 5,02 & 6,74 & 8,82 \\
\hline $\mathrm{C}_{\mathrm{N}, \mathrm{T}}(0,01)$ & 2,26 & 3,96 & 5,69 & 7,95 & 9,94 \\
\hline \multicolumn{6}{|c|}{ Norte-Nordeste } \\
\hline \multicolumn{6}{|c|}{$\mathrm{TMI} \Rightarrow$ Renda } \\
\hline$W_{\text {HNC }}$ & 1,88 & 3,94 & 7,30 & 11,23 & 13,61 \\
\hline$\tilde{Z}_{N, T}$ & 1,82 & 2,68 & 4,63 & 6,09 & 5,31 \\
\hline \multicolumn{6}{|c|}{ Renda $\Rightarrow \mathrm{TMI}$} \\
\hline$W_{\text {HNC }}$ & 0,79 & 2,63 & 3,95 & 6,74 & 6,67 \\
\hline$\tilde{Z}_{N, T}$ & $-0,69$ & 0,64 & 0,65 & 1,93 & 0,40 \\
\hline $\mathrm{C}_{\mathrm{N}, \mathrm{T}}(0,1)$ & 1,65 & 3,04 & 4,48 & 6,04 & 7,92 \\
\hline $\mathrm{C}_{\mathrm{N}, \mathrm{T}}(0,05)$ & 1,80 & 3,28 & 4,79 & 6,44 & 8,43 \\
\hline $\mathrm{C}_{\mathrm{N}, \mathrm{T}}(0,01)$ & 2,10 & 3,71 & 5,36 & 7,17 & 9,39 \\
\hline
\end{tabular}

Fonte: Cálculos do autor a partir dos dados do Ipeadata e do DATASUS. 
Tabela 7 - Escolha de Defasagens através do Critério de Schwarz

\begin{tabular}{ccccccc}
\hline & & K=1 & K=2 & K=3 & K=4 & K=5 \\
\hline \multirow{2}{*}{ Brasil } & TMl $\Rightarrow$ Renda & 10,97 & 11,41 & 11,75 & 12,13 & 12,50 \\
& Renda $\Rightarrow$ TMl & 12,65 & 12,91 & 13,30 & 13,34 & 13,81 \\
\hline \multirow{2}{*}{ Centro-Sul } & TMl $\Rightarrow$ Renda & 11,07 & 11,44 & 11,74 & 12,06 & 12,38 \\
& Renda $\Rightarrow$ TMl & 11,09 & 11,18 & 11,33 & 11,50 & 11,61 \\
\hline \multirow{2}{*}{ Norte-Nordeste } & TMl $\Rightarrow$ Renda & 10,73 & 11,12 & 11,36 & 10,65 & 11,92 \\
& Renda $\Rightarrow$ TMl & 13,03 & 13,26 & 13,61 & 13,57 & 14,01 \\
\hline
\end{tabular}

Fonte: Cálculos do autor a partir dos dados do Ipeadata e do DATASUS. 